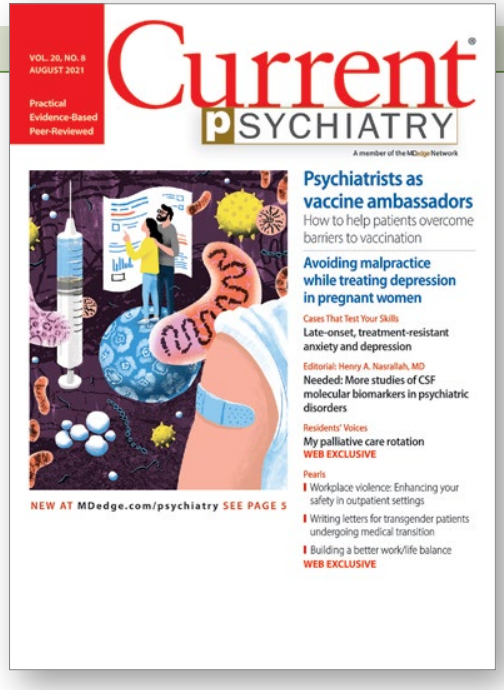

August 202

\section{Medical transition in transgender patients}

I just read the article "Writing letters for transgender patients undergoing medical transition" by Dr. Amy Riese (Pearls, Current Psychiatry, August 2021, p. 51-52). I very much appreciate this topic being brought into the light and her excellent guidelines for patients who suffer from gender dysphoria and require medical transition.

I would like to use her piece as an opportunity to highlight what has become a chasm in psychiatric care. Dr. Riese's article was on the letter itself and not the assessment of a patient with possible gender dysphoria, but assessment is barely mentioned, and is the single most important part of a gender transition process. Assessment has become the huge chasm in treatment. In my community, both personally and professionally, I have witnessed very

\section{Keep in touch!}

Ietters@currentpsychiatry.com

OR

Comments \& Controversies

CURRENT PSYCHIATRY

7 Century Drive, Suite 302

Parsippany, NJ 07054

All letters are subject to editing. little assessment taking place, yet a lot of transitioning is happening.

Concerned and caring family members take their child (or self-present if the patient is an adult) to gender specialists for their expertise. What is happening during these evaluations are brief conversations during which the gender specialist accepts a patient's (sometimes a minor's) self-diagnosis of gender dysphoria. There is discussion of the importance of being gender-affirming, and the beginning of a discussion of hormone therapy. During these discussions of hormone therapy, there is very little disclosure of some of the untoward effects. I understand this is a generalization, and there are some gender specialists who are doing excellent, thorough assessments. But this is what I am seeing in my community, to the point that I have no local specialists to whom I feel comfortable sending my patients who may have gender dysphoria.

During discussions, some of the significant medical outcomes of hormone therapy (immunosuppression, loss of bone density, sterility, increased risk of certain types of cancer, etc.) are not mentioned, or are mentioned in passing. Clinicians have begun using euphemisms such as "top surgery" or "upper body surgery," as used in Dr. Riese's article, rather than the medically accurate term, which is "bilateral mastectomy." These behaviors are being manifested by mostly well-meaning clinicians, and start the process of ushering a patient down a one-way street toward a medical transition.

In April of this year, a prestigious institution in my state did a training on aspects of treating transgender and nonbinary youth. The training advocated giving less information to transgender youth regarding the effects of treatment on fertility, arguing that giving adequate information would disrupt the normal course of development. However, we are allowing these same youth to consent for treatment.

This is a very destructive phenomenon, and only time will tell what the psychiatric outcomes will be for patients who medically transition who did not have an adequate assessment. After so much loss under the auspices of treatment, one would hope that at the very least, these children and young adults would be in a better place psychologically, that they would finally be happy and fulfilled in their new reality, that their mental anguish would evaporate, and with it, their risk of suicide. And this may be true if the patient had gender dysphoria.

But what about the patients who did not have an adequate assessment, whose self-diagnosis was accepted without question, the gender-affirming model immediately implemented, and referrals quickly made for medical treatment? For those patients, once everything has been done, every hormone taken, every surgery performed, but still not male enough, not convincingly male in every aspect, now what? Where does one go from there?

Only time will tell what the psychiatric outcomes will be for these patients, who are primarily youth and young adults at this point. What about the psychological pain that brought them to identify as transgender in the first place? Since the patient was colluded with in the diagnosis of gender dysphoria, that pain was

continued on page 36 
Comments \& Controversies continued from page 15

never identified and addressed. What will the suicide rate be of these fully transitioned patients who never had gender dysphoria?

And what shall become of the clinicians who treated them without pause or careful consideration, who bypassed informed consent, treating teens as if they had the judgment and psychological maturity of an adult? What will be their defense when the malpractice lawsuits begin to mount against them, when patients and their families emerge on the other side of the medical transition to find that life, identity, intimacy, and the most basic biological functions have been altered forever based on the capricious and suggestible whims of children?

According to the DSM-5, the prevalence of gender dysphoria is very low. Even if we were to double the DSM-5 estimate, it is still very low. As psychiatrists, we are leaders in the mental health field, and need to set the tone and guide nonphysician clinicians toward extremely careful assessment of these patients.

While Dr. Riese gives excellent information about how to write a letter for a patient who needs transition, far fewer of these letters should be written. The upward trend in the numbers of patients receiving a diagnosis, and subsequently letters, is largely imposed by clinicians who disregard the DSM- 5 and fail to apply critical thought to this assessments.

Lorie Gearhart, MD

Capitola, California

Disclosure: The author reports no financial relationships with any companies whose products are mentioned in their letter, or with manufacturers of competing products.

doi: $10.12788 /$ cp. 0187 